\title{
HUBUNGAN FAKTOR RISIKO UMUR, INDEKS MASSA TUBUH, KEBIASAAN OLAHRAGA DAN KONSUMSI KAFEIN DENGAN GEJALA OSTEOPOROSIS PADA AKSEPTOR KB DMPA DI WILAYAH PUSKESMAS TENGARAN
}

\author{
Listyaning Eko Martanti ${ }^{1)}$, Kadek Yuli Hesti ${ }^{2)}$, Yulinda Laska ${ }^{3)}$ \\ E-mail address: listy@poltekkes-smg.ac.id
}

\begin{abstract}
Osteoporosis is a health problem that results in a high incidence of morbidity, disability, decreased quality of life and mortality. Decreasing bone mass density (DMT) in women is associated with decreased estrogen levels as a contributing factor in bone formation. This can occur due to several factors such as pregnancy, breastfeeding, and long-term use of contraception, including Depo Medroxy Progesterone Acetate (DMPA) contraception. (Tahir, 2009).

This study uses a cross-sectional design. The population in this study were all DMPA KB acceptors in the Tengaran Health Center area, Semarang Regency. The sample in this study were 81 respondents. Data analysis in this study was Univariate and Bivariate using nonparametric statistical test, namely chi-square test.

The results of this study indicate that there was a correlation between age risk factors with symptoms of osteoporosis in DMPA KB acceptors in the Tengaran Region Health Center $(\mathrm{p}<0.05)$. There was no correlation between the risk factors for body mass index with symptoms of osteoporosis in DMPA KB acceptors in the Tengaran Region Health Center ( $p>0.05$ ) There is no correlation between risk factors for exercise habits with symptoms of osteoporosis in DMPA KB acceptors in the Tengaran Region Health Center ( $p>0.05)$. There is no correlation between risk factors for caffeine consumption and symptoms of osteoporosis in DMPA KB acceptors in the Tengaran Region Health Center ( $p>0.05)$.

The intake of nutrients that contain enough calcium is very necessary for DMPA $\mathrm{KB}$ acceptors, especially women who experience cessation of the menstrual cycle as an effort to prevent osteoporosis. Screening osteoporosis could be planned, especially DMPA KB acceptors aged over 35 years.

Keywords: Osteoporosis; family planning; age; BMI; caffeine consumption; sports behavior ${ }^{1)}$ Poltekkes Kemenkes Semarang

${ }^{2)}$ StiKes Mardi Rahayu Kudus

${ }^{3)}$ StiKes Awalbros Batam
\end{abstract}

\section{Pendahuluan}

Osteoporosis merupakan salah satu masalah kesehatan yang berakibat pada tingginya kejadian morbiditas, disabilitas, penurunan kualitas hidup dan mortalitas.Osteoporosis adalah berkurangnya kepadatan tulang yang progresif, sehingga tulang menjadi rapuh dan mudah patah (Setyawati, 2013). Kepadatan tulang sangat dipengaruhi oleh hormon estrogen, maka penyakit ini lebih banyak 
menyerang wanita dibanding pria. Sekitar $80 \%$ penderita osteoporosis adalah wanita, termasuk wanita muda yang mengalami penghentian siklus menstruasi atau amenorrhea. (Purwoastuti, 2009).

Data di Indonesia menunjukkan bahwa angka kejadian osteoporosis usia kurang dari 70 tahun untuk perempuan adalah sebanyak 18-36\%, sedangkan laki-laki 20-27 dan usia di atas 70 tahun untuk perempuan adalah $53.6 \%$ sedangkan laki-laki $38 \%$.Penurunan densitas massa tulang (DMT) pada perempuan dikaitkan dengan menurunnya kadar estrogen sebagai faktor yang berperan dalam pembentukan tulang. Hal ini dapat terjadi oleh karena beberapa faktor seperti kehamilan, menyusui, dan penggunaan kontrasepsi jangka panjang diantaranya adalah kontrasepsi Depo Medroxy Progesteron Asetat (DMPA). (Tahir, 2009).

DMPA merupakan jenis kontrasepsi suntikan yang memiliki mekanisme kerja mencegah ovulasi dengan cara kerja kadar Follicle Stimulating Hormone dan Luteinizing Hormone respon kelenjar Hipofise terhadap Gonadotropin Realizing Hormone tidak berubah, sehingga membawa kesan proses terjadi di hipotalamus daripada kelenjar hipofise, mengentalkan lendir serviks sehingga membuat endometrium menjadi kurang baik untuk implantasi dan ovum yang telah dibuahi. (Hartanto, 2004).

Dalam kehidupan masyarakat sehari-hari sering terlihat keluarga yang berpenghasilan cukup akan tetapi makanan yang dihidangkan seadanya. Dengan demikian, kejadian gangguan gizi tidak hanya ditemukan pada keluarga yang berpenghasilan kurang akan tetapi juga pada keluarga yang berpenghasilan relatif baik (cukup). Keadaan ini menunjukkan bahwa ketidaktahuan akan makanan bagi kesehatan tubuh mempunyai sebab buruknya mutu gizi makanan pada keluarga (Marimbi, 2010).

\section{Metode Penelitian}

Penelitian ini menggunakan desain case control. Populasi pada penelitian ini bulan Januari s.d Desember 2015 adalah 435 orang. Populasi adalah wilayah generalisasi yang terdiri atas yang mempunyai kualitas dan karakteristik tertentu yang ditetapkan oleh peneliti untuk dipelajari dan kemudian ditarik kesimpulannya. (Sugiyono, 2009). Sampel adalah bagian dari jumlah dan karakteristik yang dimiliki oleh populasi tersebut. (Sugiyono, 2009). Sampel dalam penelitian ini sejumlah 81 responden.

Teknik pengambilan sampel adalah suatu cara mengambil sampel yang representative dari populasi yang dilakukan sedemikian rupa sehingga diperoleh sampel yang benar-benar dapat mewakili dan dapat menggambarkan keadaan populasi yang sebenarnya. Pengambilan anggota sampel dari populasi dilakukan secara accidental sampling yaitu cara pengambilan sampel seketemunya. (Santjaka, 2011).

Sampel terbagi menjadi 2 kelompok yang terdiri dari kelompok kasus yaitu akseptor KB DMPA jangka panjang dan kelompok kontrol yaitu akseptor KB non DMPA.Pengambilan data dilakukan dengan mengukur berat badan dan mengukur tinggi badan responden dengan alat yang sama untuk mengukur seluruh responden. 
Untuk mengukur variabel kebiasaan olahraga dilakukan dengan memberikan angket kepada responden yang memuat perilaku atau kebiasaan olahraga yang dilakukan selama seminggu serta konsumsi kafein oleh responden per hari.Responden akan diberikan kuesioner untuk mengukur gejala osteoporosis yang dirasakan selama menjadi akseptor KB DMPA.

\section{Hasil dan Pembahasan}

Tabel 1. Distribusi responden berdasarkan umur, IMT, Kebiasaan OR dan Konsumsi kafein

\begin{tabular}{lcc}
\hline \multicolumn{1}{c}{ Variabel } & $\mathrm{N}$ & $\%$ \\
\hline Umur (tahun) & & \\
$<35$ & 55 & 67.9 \\
$\geq 35$ & 26 & 32.1 \\
\hline IMT & & \\
Kurus & 10 & 12.3 \\
Normal & 51 & 63 \\
Gemuk & 21 & 24.7 \\
\hline Kebiasaan OR & & \\
Ya & 13 & 16 \\
Tidak & 68 & 84 \\
\hline Konsumsi Kafein & & \\
$>300$ mg/hari & 27 & 33.3 \\
$<300 \mathrm{mg} /$ hari & 54 & 66.7 \\
\hline
\end{tabular}

Tabel 1 menunjukkan bahwa sebagian besar umur responden adalah $<35$ tahun sejumlah $67.9 \%$, indeks massa tubuh akseptor KB DMPA adalah normal (63\%), akseptor KB DMPA tidak berolahraga (84\%), akseptor $\mathrm{KB}$ DMPA yang mengkonsumsi kafein < $300 \mathrm{mg} /$ hari (66.7)

Tabel 2. Analisis hubungan antara

\begin{tabular}{ccccc}
\hline \multirow{2}{*}{$\begin{array}{c}\text { Umur } \\
\text { (tahun) }\end{array}$} & \multicolumn{2}{c}{$\begin{array}{c}\text { Gejala } \\
\text { Osteoporosis }\end{array}$} & Jumlah & $\begin{array}{c}\text { p- } \\
\text { value }\end{array}$ \\
\cline { 2 - 3 } & Ya & Tidak & & \\
\hline$<35$ & 9 & 46 & 55 & 0.000 \\
$\geq 35$ & 23 & 3 & 26 & \\
\hline Jumlah & 32 & 49 & 81 & \\
\hline
\end{tabular}

umur dengan gejala osteoporosis pada akseptor KB DMPA.

Hasil penelitian menunjukkan bahwa umur memliki p-value $<0.05$ yang dapat disimpulkan bahwa umur akseptor DMPA memliki hubungan yang signifikan dengan gejala osteoporosis. Didukung oleh penelitian Lukman (2008) bahwa terdapat hubungan yang signifikan antara usia dan kejadian osteoporosis di Desa Cijambu (p value <0,05).

Semakin tua umur seseorang, risiko terkena osteoporosis menjadi semakin besar karena proses densitas (kepadatan) tulang hanya berlangsung sampai seseorang berumur 25 tahun. Selanjutnya, kondisi tulang akan tetap konstan hingga usia 40 tahun. Setelah umur 40 tahun, densitas tulang mulai berkurang secara perlahan. Oleh karenanya, massa tulang akan berkurang seiring dengan proses penuaan. Berkurangnya massa tulang ini akan berlangsung terus sepanjang sisa hidup (Wirakusumah, 2007).

Tabel 3. Analisis hubungan antara IMT dengan gejala osteoporosis pada akseptor KB DMPA

\begin{tabular}{ccccc}
\hline \multirow{2}{*}{ IMT } & \multicolumn{2}{c}{$\begin{array}{c}\text { Gejala } \\
\text { Osteoporosis }\end{array}$} & Jumlah & $\begin{array}{c}\mathrm{p}- \\
\text { value }\end{array}$ \\
\cline { 2 - 3 } & Ya & Tidak & & \\
\hline Kurus & 4 & 6 & 10 & 0,708 \\
Normal & 21 & 30 & 51 & \\
Gemuk & 7 & 13 & 20 & \\
\hline Jumlah & 32 & 49 & 81 & \\
\hline
\end{tabular}

Hasil perhitungan bahwa pvalue sebesar 0,708 atau >0,05 artinya ada tidak hubungan yang signifikan antara indeks massa tubuh dengan gejala osteoporosis.

Indeks massa tubuh merupakan indikator yang praktis untuk menentukan status gizi. Data Riskesdas 2007 menunjukkan tingginya 
prevalensi indeks massa tubuh (IMT) rendah atau kurus di Indonesia. Prevalensi IMT rendah atau kurus, yakni sebanyak 14,8 persen pada orang dewasa. Perempuan bertubuh ramping/kurus dan bertulang kecil berisiko lebih besar memiliki DMT rendah daripada yang kelebihan berat badan/gemuk dan bertulang besarnamun Hasil penelitian ini menunjukkan bahwa $\mathrm{p}$ value korelasi indeks massa tubuh dengan gejala osteoporosis adalah 0.708 atau $>0.05$ yang artinya tidak terdapat hubungan yang signifikan antara indeks massa tubuh dengan gejala osteoporosis. Seperti halnya hasil penelitian Setyawati (2011) bahwa tidak ditemui hubungan antara IMT dan DMT ( $p>0,05)$. Serta pernyataan Robbins et al (2006) menyatakan bahwa IMT bukanlah prediktor yang baik untuk DMT.

Tabel 4. Analisis hubungan antara Kebiasaan Olahraga dengan Gejala Osteoporosis

\begin{tabular}{ccccc}
\hline \multirow{2}{*}{$\begin{array}{c}\text { Kebiasaan } \\
\text { olahraga }\end{array}$} & \multicolumn{2}{c}{$\begin{array}{c}\text { Gejala } \\
\text { Osteoporosis }\end{array}$} & Jmlh & $\begin{array}{c}\text { p- } \\
\text { value }\end{array}$ \\
\cline { 2 - 3 } & Ya & Tidak & & \\
\hline Ya & 3 & 10 & 13 & 0,191 \\
Tidak & 29 & 39 & 68 & \\
\hline Jumlah & 32 & 49 & 81 & \\
\hline
\end{tabular}

Perhitungan p-value sebesar 0,191 atau > 0.05 yang artinya tidak ada hubungan yang signifikan antara kebiasaan olahraga dengan gejala osteoporosis.

Gaya hidup seperti kurangnya aktivitas fisik (olahraga), kebiasaan merokok dan konsumsi kafein juga dapat meningkatkan risiko terjadinya osteoporosis (Lane, 2001). Hasil penelitian Mira Trisyani dkk menunjukkan bahwa $70,8 \%$ responden tidak melakukan olahraga secara teratur, $88,75 \%$ mempunyai kebiasaan konsumsi kafein dapat mempengaruhi terjadinya osteoporosis. Hal ini terjadi karena proses pembentukan tulang akan terganggu dan mempercepat pengeroposan tulang (Trisyani dkk, 2004).

Wanita yang malas bergerak atau berolahraga akan terhambat proses osteoblasnya. Selain itu kepadatan massa tulang akan berkurang. Semakin banyak bergerak dan olahraga maka otot akan memacu tulang untuk membentuk massa (Zaviera, 2008). Semakin rendah aktivitas fisik, semakin besar risiko terkena osteoporosis. Hal ini terjadi karena aktivitas fisik (olahraga) dapat membangun tulang dan otot menjadi lebih kuat, juga meningkatkan keseimbangan metabolisme tubuh.

Namun pada penelitian ini tidak terdapat hubungan antara kebiasaan olahraga dengan gejala osteoporosis ( $\mathrm{p}$ $>0.05)$. Hal ini dapat terjadi karena status gizi yang seimbang pada akseptor DMPA dan faktor lain yang tidak peneliti lakukan pada penelitian ini.

Tabel 5. Analisis bivariat hubungan antara konsumsi kafein dengan gejala osteoporosis pada akseptor KB DMPA

\begin{tabular}{ccccc}
\hline \multirow{2}{*}{$\begin{array}{c}\text { Konsumsi } \\
\text { kafein }\end{array}$} & \multicolumn{2}{c}{$\begin{array}{c}\text { Gejala } \\
\text { Osteoporosis }\end{array}$} & \multirow{2}{*}{ Jml } & $\begin{array}{c}\text { p- } \\
\text { value }\end{array}$ \\
\cline { 2 - 4 } & Ya & Tidak & & \\
\hline$<300 \mathrm{mg} / \mathrm{hr}$ & 20 & 34 & 54 & 0.526 \\
$>300 \mathrm{mg} / \mathrm{hr}$ & 12 & 15 & 27 & \\
\hline Jumlah & 32 & 49 & 81 & \\
\hline
\end{tabular}

Perhitungan p-value sebesar 0,526 atau > 0.05 yang artinya tidak ada hubungan yang signifikan antara kebiasaan olahraga dengan gejala osteoporosis.

Konsumsi kafein menjadi gaya hidup yang menyumbang terjadinya 
osteoporosis. Minuman yang mengandung tinggi kafein yaitu kopi sedangkan teh, minuman berkarbonasi, suplemen, dan minuman berenergi memiliki kandungan kafein $\leq 50 \mathrm{mg}$. Konsumsi kafein $\geq 300 \mathrm{mg} / \mathrm{hari}$ menyebabkan efek yang negatif pada metabolisme kalsium, termasuk meningkatkan konsentrasi kalsium pada urin dan plasma, menurunkan kepadatan mineral tulang dan menurunkan volume tulang pada wanita postmenopausal. Kafein yang dikonsumsi berlebih akan meningkatkan konsentrasi kalsium pada urin dan plasma. Pada Hasil penelitian ini tidak tampak adanya hubungan yang signifikan antara konsumsi kafein dengan gejala osteoporosis $(\mathrm{P}>0.05)$. Berdasarkan banyak penelitian, 100 gram kafein dalam kopi akan membuang 2-3 miligram kalsium dalam tubuh. National Osteoporosis Foundation menyatakan bahwa minum kopi akan berisiko osteoporosis bila memang sudah mengalami pengurangan kepadatan tulang, atau osteoporosis. Namun, kafein dalam kopi tidak akan menimbulkan osteoporosis selama mengonsumsi kalsium yang cukup dari makanan dan minuman yang lain. Selain itu, gaya hidup seperti kurang olahraga dan merokok justru lebih memicu osteoporosis dibandingkan konsumsi kopi. (Spiritia, 2011).

\section{Simpulan}

Hasil penelitian menunjukkan terdapat hubungan faktor risiko umur dengan gejala osteoporosis pada akseptor KB DMPA di Puskesmas Wilayah Tengaran $(\mathrm{p}<0.05)$, tidak terdapat hubungan faktor risiko indeks massa tubuh dengan gejala osteoporosis pada akseptor KB DMPA di Puskesmas Wilayah Tengaran ( $\mathrm{p}>0.05$ ), tidak terdapat hubungan faktor risiko kebiasaan olahraga dengan gejala osteoporosis pada akseptor KB DMPA di Puskesmas Wilayah Tengaran ( $p>0.05)$, tidak terdapat hubungan faktor risiko konsumsi kafein dengan gejala osteoporosis pada akseptor KB DMPA di Puskesmas Wilayah Tengaran $(p>0.05)$.

Adapun saran terkait dengan penelitian ini adalah asupan nutrisi yang cukup mengandung kalsium sangat diperlukan terutama bagi wanita yang mengalami penghentian siklus menstruasi sebagai upaya pencegahan osteoporosis, Screening osteoporosis dapat direncanakan terutama akseptor KB DMPA dengan usia lebih dari 35 tahun.

\section{Daftar Pustaka}

Admin. Cara Tepat Hindari Osteoporosis Dini. www. health.kompas.com. 2014. Diakses pada tanggal 22 Februari 2016.

Baziad, Ali. Menopause dan Andropause. Yayasan Bina Pustaka. Jakarta. 2003

Badan Penelitian dan Pengembangan Kesehatan. Riset Kesehatan Dasar (Riskesdas) 2007: Laporan Nasional. Jakarta: Badan Litbangkes Depkes, 2008.

Boroditsky dan Rachman (11 \& 14) dalam Tahir. Gambaran densitas mineral tulang vertebra lumbal akseptor KB suntik DMPA.2009.

Budiarto, Eko. Pengantar Epidemiologi. EGC. 2003.

Emma S. Wirakusumah. Mencegah Osteoporosis. Penebar plus. Jakarta. 2007. 
Genant HK, Cooper C, Poor G, ReidI, Ehrlich G, Kanis J, et al. Interim Report and Recommendations of the World Health Organization Task-Force for Osteoporosis. Osteoporos Int. 1999; 10(4): 25964. dalam Budi Setyawati, Sri Prihatini, Wasilah Rochmah dan Retno Pangastuti Hubungan Indeks Massa Tubuh Dengan Densitas Mineral Tulang Pada Perempuan Dewasa Muda. 2013.

Hanafi, Hartanto. 2004 dalam Haryati Nani. DMPA terhadap kenaikan $B B$ di BPS Supriyatni Desa Pakitengan Kabupaten Cilacap Tahun 2010.

Hermastuti A dan Isnawati M. Hubungan Indeks Massa Tubuh, Massa Lemak Tubuh, Asupan Kalsium, Aktivitas Fisik dan Kepadatan Tulang pada Wanita Dewasa Muda. Journal of Nutrition Collage. 2012; Vol 1 (1).

Kaunitz and Scholes (14 \&15) dalam WHEC Practice Bulletin and Clinical Management Guidelines for healthcare providers. (Contraception $\left.D M P A \_B M D\right)$.

Kawiyana, I Ketut Siki. Osteoporosis Patogenesis Diagnosis dan Penanganan Terkini. J Peny Dalam. 2009; Vol. 10

Leveno, et al. Obstetri Williams Panduan Ringkas. EGC. Jakarta. 2009.

Notoatmodjo. Metodologi Penelitian Kesehatan. Rineka Cipta. Jakarta. 2010.

Purwoastuti, Endang. Waspada Osteoporosis. Kanisius.

Yogyakarta. 2009.

RS Bethesda Yogyakarta. Program Pelayanan Osteoporosis (Pengeroposan Tulang).
Diakses pada 15 Juni 2015 http://bethesda.or.id/pelayanan/ 81/osteoporosis

$\% 28$ pengeroposan_tulang\%29. $\mathrm{html}$

Riggs and Cooper (3\&4) dalam Tahir. Gambaran densitas mineral tulang vertebra lumbal akseptor $\quad K B \quad$ suntik DMPA.2009.

Riwidikdo. Statistik untuk Penelitian Kesehatan. Pustaka Insani; Yogyakarta. 2009

Robbins J, Schott AM, Azari R, Kronmal R. Body mass index is not a good predictor of bone density: results from WHI, CHS, and EPIDOS. J Clin Densitom. 2006; 9(3): 329-34.

Salma. Beberapa Fakta Penting Mengenai Kalsium. Diakses tanggal 12 Juni 2015 dari http://majalahkesehatan.com/beber apa-fakta-penting-mengenaikalsium/

Setyawati. Hubungan Indeks Massa Tubuh dengan Densitas Minteral Tulang pada Perempuan Dewasa Muda. Fakultas Kedokteran UGM Yogyakarta. 2011

Sugiyono. Metode Penelitian Kuantitatif Kualitatif dan $R \& D$. CV Alfabeta. Bandung. 2009.

Suhardjo dkk. Prinsip-prinsip Ilmu Gizi. Kanisius. Yogyakarta. 2010

Tahir, A.M, Gambaran Densitas Mineral Tulang Vertebra Lumbal Akseptor KB Suntik DMPA. I Obstetri Ginekologi Indone: 2009; Vol 33

Trade Journals. Contraceptive Technology Update.AHC Media LLC. ProQuest Public Health. 2011 Tee, E-Siong dan Rodolfo F. Florentino. Recommended Dietari 
Zaviera, Ferdinand. Osteoporosis: Deteksi Dini, Penanganan dan

Terapi Praktis. Ar-Ruzz Media. Yogyakarta. 2008

Allowances (RDA), Armonization in Southest Asia. ILSI. Singapore. 2005.

Trihapsari, Enita. Faktor-faktor yang berhubungan dengan densitas mineral tulang wanita $\geq 45$ tahun di Departemen Pendidikan Nasional Jakarta Pusat. 2009.

Tusmantoyo, dkk, Efek Pemberian Susu Kambing Peranakan Ettawa terhadap Densitas

Tulang Femur pada Tikus Wistar Jantan. 2014 